\title{
Trousseau's Syndrome Anticipating Lung Adenocarcinoma: A Combination of Novel Direct Oral Anticoagulant and Osimertinib to Treat It
}

\section{Irene Pecora $^{1 *}$ | Carmelo Tibaldi ${ }^{2}$ | Elisabetta Perrone ${ }^{3}$ | Laura Bassani ${ }^{3}$ | Editta Baldini ${ }^{2}$}

*Correspondence: Irene Pecora

Address: ${ }^{1}$ Department of Medical Oncology, Misericordia Hospital, Via Senese, 161, 58100 Grosseto, GR, Italy; ${ }^{2}$ Department of Medical Oncology, S. Luca Hospital, Via Guglielmo Lippi Francesconi 556, 55100 Lucca, LU, Italy; ${ }^{3}$ Department of Radiology, S. Luca Hospital, Via Guglielmo Lippi Francesconi 556, 55100 Lucca, LU, Italy

e-mail $\bowtie$ irene.pecora@gmail.com

Received: 17 February 2021; Accepted: 01 March 2021

Copyright: (C) 2021 Pecora I, et al. This is an open-access article distributed under the terms of the Creative Commons Attribution License, which permits unrestricted use, distribution, and reproduction in any medium, provided the original author and source are credited.

\section{ABSTRACT}

Trousseau's syndrome was the unexpected manifestation of thrombotic events, often associated with the diagnosis of malignancies, since cancer has been recognized as a prothrombotic state. There is a wide experience using low molecular weight heparin or Fondaparinux, while the use of direct oral anticoagulants, as Rivaroxaban, had less extent.

A 76-year-old woman was diagnosed by a Trousseau's syndrome, with multiple arterial and venous thrombotic events, representing the alarm signals of an advanced non-small cell lung cancer (NSCLC). The patient's burden of disease rapidly widespread, with unexpected and polidistrectual thrombotic events and an advanced NSCLC with pleural effusion carrying EGFR mutation.

After the treatment with an inhibitor of activated Factor X, the thrombotic events did not stop. Starting new direct oral anticoagulant drug and the oral EGFR Tyrosine Kinase Inhibitor (TKI), according to the molecular features of lung cancer, she rapidly achieved good response on overall global burden of disease.

The aim of this article was to report a case of Trousseau's syndrome anticipating lung cancer diagnosis that was successfully treated with a quick start of proper anticoagulant and targeted oncological treatments. The interruption of thromboembolic events represented the first sign of disease response to treatments.

Keywords: Trousseau's Syndrome, Thromboses, Osimertinib, Adenocarcinoma, NSCLC, EGFR

\section{Introduction and Background}

In the chapter titled "Phlegmatia alba dolens", from one of his important work published in France in 1865, the Parisian physician Armand Trousseau firstly described the association between cancer and migratory thrombophlebitis (Trousseau, 1865) and also suggested to screen for malignancies if 
recurrent or idiopathic thromboembolic disease occur (Khorana, 2003; Piccioli et al., 2004). Two years later, after the diagnosis of the problem on himself, unfortunately he died because of a gastric cancer.

Since the first description, Trousseau's syndrome, as it was called, was referred to the manifestation of unexpected thrombotic events that precede the diagnosis of an occult visceral tumour or appear concomitantly with it (Varki, 2007). Some cancers were found to be more often complicated by thromboembolic events: lung, pancreatic, brain, ovarian, renal, uterine, and gastric cancers (Sorensen, 2000; Chew et al., 2006). Of note, lung cancer patients are at a 20-fold higher risk for the development of thromboses compared with the general population (Blom et al., 2004).

The clinical manifestations of cancer-associated thrombosis involves a wide spectrum of manifestations, as deep vein thrombosis (DVT), pulmonary embolism (PE), chronic disseminated intravascular coagulation (DIC) associated with non-bacterial thrombotic endocarditis (NBTE) and arterial thrombosis, as also described by Sack in 1977 (Sack et al., 1977). The reasons of these multiple presentations could be find in some pro-thrombotic agents produced by tumour cells such as tissue factor (TF), that is involved in activation of clotting cascade as well as in tumour growth, angiogenesis, and metastases; mucin, cysteine proteinase (CP) and plasminogen activator inhibitor -1 (PAI-1) are other involved agents (Varki et al., 2007; Kasthuri et al., 2009; Sato et al., 2006).

We herein describe the case of a woman concomitantly diagnosed by a Trousseau's syndrome and an advanced non-small cell lung cancer (NSCLC) carrying EGFR mutation, successfully treated with a combination of anticoagulant agents and targeting-EGFR therapy.

\section{Case Presentation}

On May 2020, a 76-year-old woman never smoker was referred to our hospital with a twomonths-history of dyspnoea, worsening asthenia and cough, without pyrexia.

In her clinical history, no particular events occurred; exception made for diabetes mellitus and well controlled arterial hypertension.

On March 2020, our patient accessed the Emergency room of our hospital because of an acute respiratory syndrome.

A physical examination performed on admission showed a low-grade fever and tachycardia with no other significant abnormalities. Nasopharyngeal swab for SARS-CoV2 was negative. Blood tests revealed increased D-dimer and a chest radiograph showed a right pleural effusion and concomitant multiple pulmonary nodules. 
A contrast-enhanced computed tomography (CT) of the chest and abdomen was performed. As suspected, it showed pulmonary thromboembolism, but also revealed multiple arterial and venous thromboses. Indeed, it demonstrated occlusion of the segmental branches of pulmonary arteries for both right and left lobes, occlusion of celiac trunk at its origin and along its course, occlusion at the proximal part of common hepatic artery and splenic artery, and occlusion at the proximal tract of splenic vein, with an area of splenic infarction. Simultaneously, CT scan documented a $2.1 \times 2.0-\mathrm{cm}$ nodule in the upper lobe of the right lung attached to anterior parietal and mediastinal pleura, multiple confluent lymphadenopathy of the mediastinum, multifocal and bilateral pleural thickening, and right pleural effusion.

A multidisciplinary expert consultation was held. According to imaging and clinical manifestations, the patient was a candidate for anticoagulant treatment with Fondaparinux, an inhibitor of activated Factor $\mathrm{X}$, at the dose of $7.5 \mathrm{mg}$ daily and oxygen therapy; then, a complete staging evaluation for suspected primary lung cancer was programmed.

A trans-bronchial needle aspiration (TBNA) of the right-sided hilar lymph node, performed with ultrasonic bronchoscopy, documented an adenocarcinoma positive for thyroid transcription factor-1 (TTF-1) at the histopathological examination. The advanced stage of disease was confirmed at the positron emission tomography (18FDG-PET), also demonstrating pathological cervical and axillary lymph nodes. The CT scan of the brain did not show metastasis. Genetic testing was not required.

The final diagnosis was lung adenocarcinoma, cT3N3M1a, stage IV (AJCC, TNM VIII edition, 2017). The molecular characterisation showed an EGFR mutation (p.L858R point mutation in exon 21), absence of other mutations (KRAS, BRAF, NRAS, PIK3CA, ALK, ERBB2, DDR2, MAP2KI, RET), no rearrangements in ALK or ROS1, PD-L1 with a slight positivity (around 1\%).

According to NSCLC molecular tests and stage of disease, the patient started Osimertinib $80 \mathrm{mg}$ tablet, one tablet per day, as per FLAURA trial (Soria et al., 2018), while continuing subcutaneous Fondaparinux at the same schedule.

Unfortunately, one week later, because of a limb and an arm pain, she performed a venous ultrasonography of lower limbs and upper arms that demonstrated thromboses of popliteal and small saphenous right veins and thromboses of left brachial vein. The patient was admitted to Cardiology Unit.

At the admission, blood tests were performed (Table 1). 
Table 1: Laboratory data evaluated on admission in Cardiology department. PT-INR: prothrombin time international normalized ratio, APTT: activated partial thromboplastin time, CRP: C-Reactive Protein, CEA: carcinoembryonic antigen.

\begin{tabular}{|l|l|l|l|}
\hline Hematology & \multicolumn{3}{l|}{ Biochemistry } \\
\hline White blood cells & $15580 / \mathrm{mcl}$ & AST & $24.0 \mathrm{U} / \mathrm{L}$ \\
\hline Red Blood Cells & $4.76 \mathrm{mil} / \mathrm{mcl}$ & ALT & $27.0 \mathrm{U} / \mathrm{L}$ \\
\hline Hemoglobin & $12.9 \mathrm{~g} / \mathrm{dL}$ & LDH & $434 \mathrm{U} / \mathrm{L}$ \\
\hline Hematocrit & $39.8 \%$ & Total bilirubin & $0.27 \mathrm{mg} / \mathrm{dL}$ \\
\hline Platelets & $313000 / \mathrm{mcl}$ & Creatinine & $0.86 \mathrm{mg} / \mathrm{dL}$ \\
\hline Coagulation & & Na & $140 \mathrm{mEq} / \mathrm{dL}$ \\
\hline PT-INR & 1.61 & K & $4.3 \mathrm{mEq} / \mathrm{dL}$ \\
\hline APTT & $33 \mathrm{sec}$ & Urea & $37 \mathrm{mg} / \mathrm{dL}$ \\
\hline Fibrinogen & $203 \mathrm{mg} / \mathrm{dL}$ & Serology & \\
\hline D-dimer & $6695 \mathrm{ng} / \mathrm{mL}$ & CEA & $\mathrm{ND}$ \\
\hline Antitrombin III & $109 \%$ & CRP & $2.26 \mathrm{mg} / \mathrm{dL}$ \\
\hline
\end{tabular}

Moreover, an echocardiography documented a thrombotic vegetation in right cardiac ventricle, confirmed at computed tomography pulmonary angiography. Since the unexpected, recurrent and rapidly occurring thrombotic events, the cardiology team decided to replace Fondaparinux with oral Rivaroxaban, a factor Xa inhibitor, at the dosage of $15 \mathrm{mg}$ twice daily.

Since then, after only two weeks of proper treatments, both anticoagulant and oncological ones, no other thromboembolic events of DVP or PE or NBTE occurred and a new chest CT scan reported that primary and metastatic lesions were dimensionally reduced and thromboses lesions were stable, without new ones (Fig. 1-3).

1A

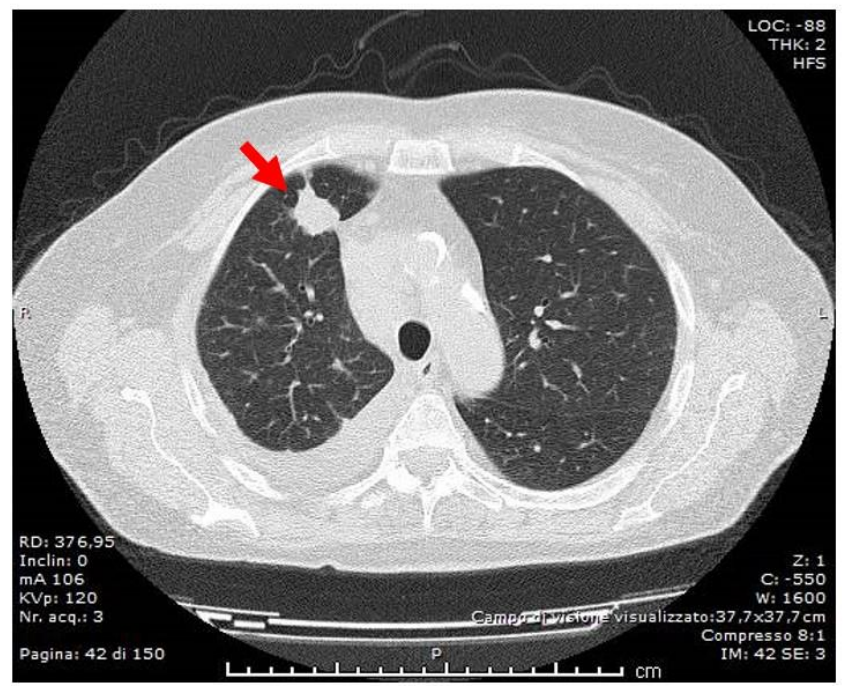

1B

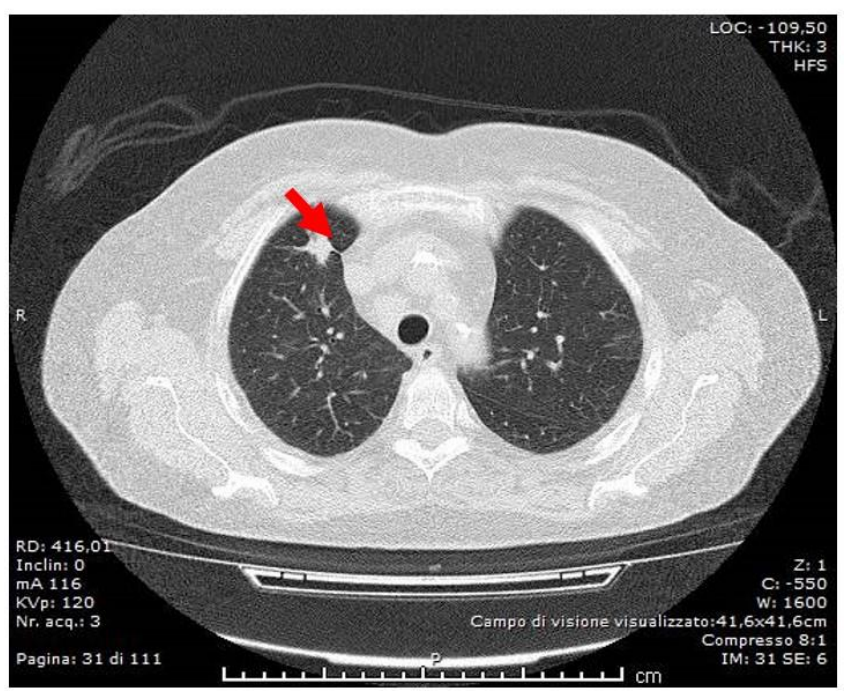

Figure 1: Computed tomography (CT) scans. Focus on primary tumour at baseline (1A) and at first evaluation (1B). 
2A

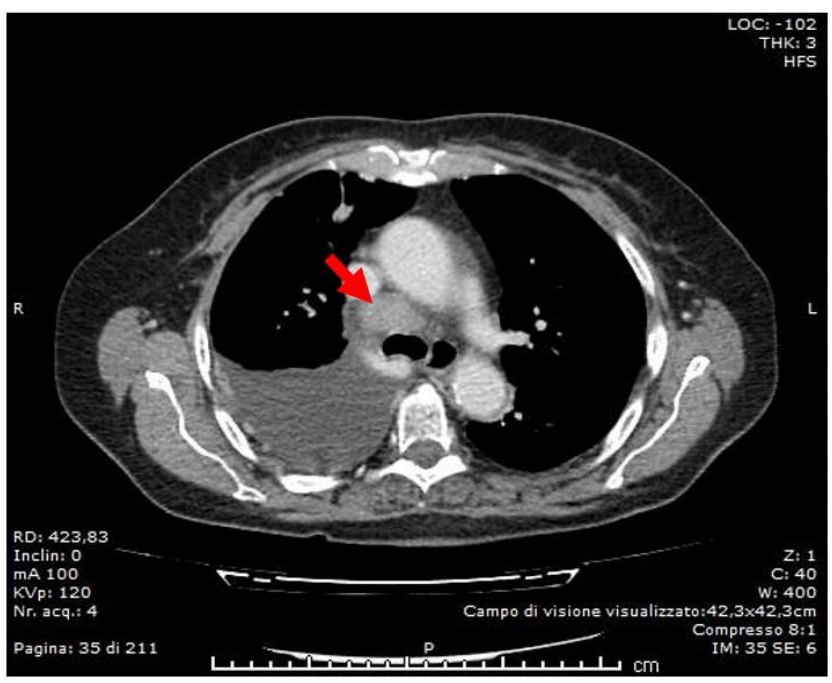

2B

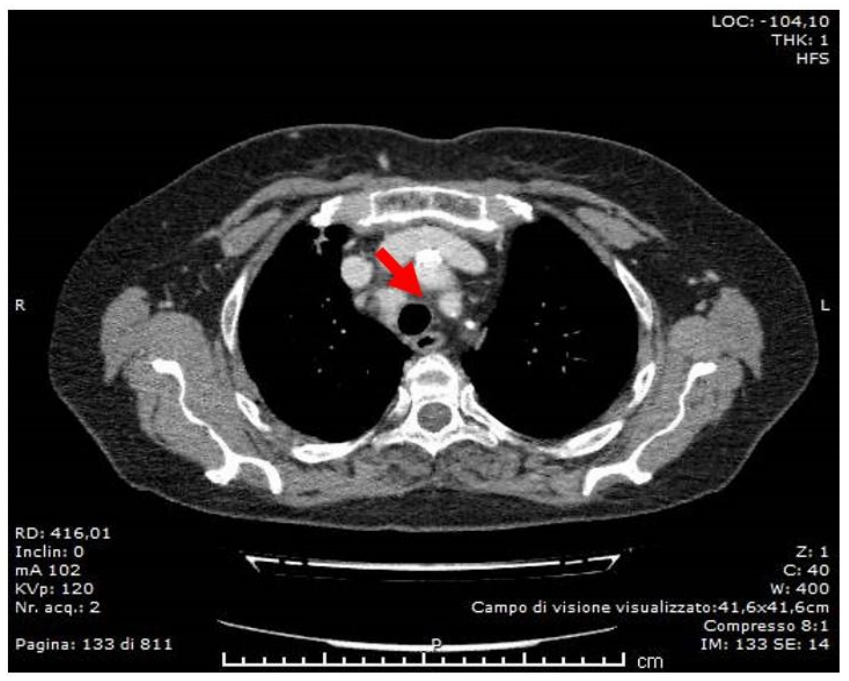

Figure 2: Computed tomography (CT) scans. Focus on mediastinal lymph adenopathy at baseline (2A) and at first evaluation (2B).

3A

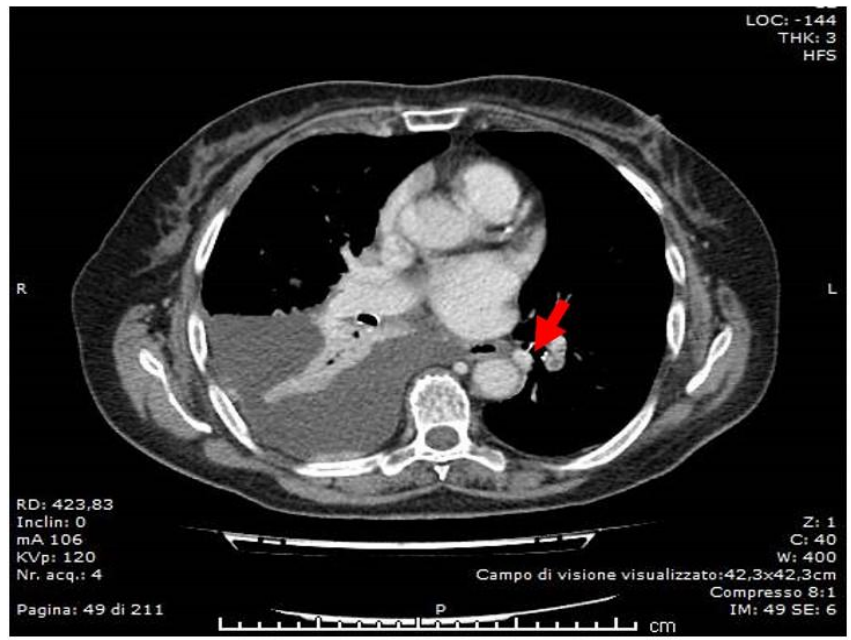

3B

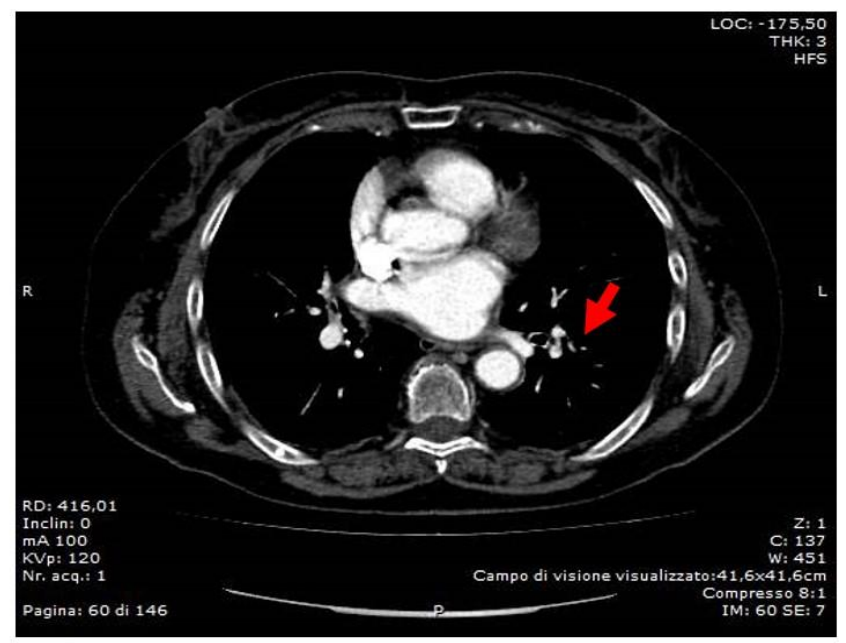

Figure 3: Computed tomography (CT) scans. Focus on pulmonary thromboembolism at baseline (3A) and at first evaluation (3B).

Consecutive three-monthly CT scans of the chest, abdomen and brain showed a partial response according to RECIST 1.1 (Schwartz et al., 2016).

Nowadays, at January 2021, the patient is receiving Osimertinib per os $80 \mathrm{mg}$ per day and Rivaroxaban per os $20 \mathrm{mg}$ per day (latter dose readjusted after one month). Her performance status was good, with a great clinical benefit, good tolerance to therapies and no thrombotic or bleeding manifestations. 


\section{Discussion and Conclusion}

Trousseau's syndrome is a cancer-associated thrombosis characterized by spontaneous, recurrent, and often migratory episodes of venous thrombosis with or without arterial embolism, due to non-bacterial thrombotic endocarditis, in patients with a solid tumour (Ikushima et al., 2016; Callander and Rapaport, 1993). Effective prophylaxis and treatment of venous thromboembolism reduces morbidity and mortality, but anticoagulant therapy alone without oncologic treatment could be ineffective (Ikushima et al., 2016).

We reported a case of a patient with unexpected and multiple thrombotic events that precede the diagnosis of pulmonary adenocarcinoma EGFR-mutated. After multiple thrombotic events, the true early "marker" of Osimertinib efficacy on tumour was represented by the absence of new ones, in association with a rapid tumour response.

We cannot exclude that a part of thrombotic events could be induced by Osimertinib, as reported by Shiroyama, et al. in their clinical report (Shiroyama et al., 2017), also taking into account that in the phase II AURA2 trial the possibility of pulmonary embolism was reported in $3 \%(n=7)$ of patients $(<1 \%$ with possible relation to treatment) (Goss et al., 2016). However, in our report, the events occurred before Osimertinib start and they presented the characteristics of the Trousseau's cancer related syndrome, repeating unexpectedly until when the time on treatment became sufficient to achieve a first disease control. Moreover, in phase III AURA 3 and FLAURA 3 study no drug-related PE events were reported (Mok et al., 2017; Ramalingam et al., 2020), while in a real-world experience the percentage of incidence was around 1.7\% (Cho et al., 2020).

Furthermore, our case incorporates and supports the new data on cancer thrombosis and direct oral anticoagulants, as Rivaroxaban or Edoxaban, recently added to major guidelines for the treatment of PE in cancer, in selected patients (Farge et al., 2019; Konstantinides et al., 2020; Khorana et al., 2018; Agnelli et al., 2020).

In conclusion, here we described the case of a woman firstly diagnosed by a Trousseau's syndrome, which opened the way to the simultaneous diagnosis of advanced oncogene-addicted NSCLC. As two sides of the same coin, they required a combination of both oral anticoagulant and target therapy to be successfully overcame. Although there is no established biomarker to predict the point of fragility of this balance, we speculate that continuous and synergistic effect of anticoagulant and target treatments, to control thromboembolic events, and possibly suppress tumour, may improve the general condition of patients and facilitate the systemic disease control and probably the subsequent treatment strategies. 
Footnotes: Informed consent statement: Consent was obtained from the patient prior to case report writing. The consent was both written and verbal. The patient gladly authorize the authors to use her clinical data and to share her clinical history, duly anonymized, in order to allow research and scientific divulgation.

Conflict-of-Interest Statement: The authors declare no conflicts of interest.

Author Contributions: E.B. designed the report; all authors collected the patient's clinical data; E.B. and I.P. analyzed the data and wrote the paper.

\section{References}

Agnelli G, Becattini C, Meyer G, Muñoz A, Huisman MV, Connors JM, Cohen A, Bauersachs R, Brenner B, Torbicki A, Sueiro MR. Apixaban for the treatment of venous thromboembolism associated with cancer. N Engl J Med 2020; 382: 15991607.

Blom JW, Osanto S, Rosendaal FR. The risk of a venous thrombotic event in lung cancer patients: Higher risk for adenocarcinoma than squamous cell carcinoma. J Thromb Haemost 2004; 2: 1760-1765.

Callander N and Rapaport SI. Trousseau's syndrome. West J Med 1993; 158: 364-371.

Chew HK, Wun T, Harvey D, Zhou H, White RH. Incidence of venous thromboembolism and its effect on survival among patients with common cancers. Arch Intern Med 2006; 166: 458-464.

Cho BC, Kim DW, Park K, Lee JS, Yoo SS, Kang JH, Lee SY, Kim CH, Jang SH, Kim YC, Yoon HK. Real-world use of osimertinib in non-small cell lung cancer: ASTRIS study Korean subgroup analysis. Curr Med Res Opin 2020; 36: 477-482.

Farge D, Debourdeau P, Beckers M, Baglin C, Bauersachs RM, Brenner B, Brilhante D, Falanga A, Gerotzafias GT, Haim N, Kakkar AK. International Clinical Practice Guidelines for the Treatment and Prophylaxis of Venous Thromboembolism in Patients with Cancer. Lancet Oncol 2019; 20: e566-e581.

Goss G, Tsai CM, Shepherd FA, Bazhenova L, Lee JS, Chang GC, Crino L, Satouchi M, Chu Q, Hida T, Han JY. Osimertinib for pretreated EGFR Thr790Met-positive advanced non-small-cell lung cancer (AURA2): a multicentre, open-label, single-arm, phase 2 study. Lancet Oncol 2016; 17: 1643-1652.

Ikushima S, Ono R, Fukuda K, Sakayori M, Awano N, Kondo K. Trousseau's syndrome: Cancer-associated thrombosis. Jpn J Clin Oncol 2016; 46: 204-208.

Kasthuri RS, Taubman MB, Mackman N. Role of tissue factor in cancer. J Clin Oncol 2009; 27: 4834-4838.

Khorana AA, Noble S, Lee AY, Soff G, Meyer G, O'Connell C, Carrier M. Role of direct oral anticoagulants in the treatment of cancer-associated venous thromboembolism: guidance from the SSC of the ISTH. J Thromb Haemost 2018; 16: 1891-1894.

Khorana AA. Malignancy, thrombosis and Trousseau: The case for an eponym. J Thromb Haemost 2003; 1: 2463-2465.

Konstantinides SV, Meyer G, Becattini C, Bueno H, Geersing GJ, Harjola VP, Huisman MV, Humbert M, Jennings CS, Jiménez D, Kucher N. 2019 ESC Guidelines for the diagnosis and management of acute pulmonary embolism developed in collaboration with the European respiratory society (ERS). Eur Heart J 2020; 41: 543-603.

Mok TS, Wu YL, Ahn MJ, Garassino MC, Kim HR, Ramalingam SS, Shepherd FA, He Y, Akamatsu H, Theelen WS, Lee CK. Osimertinib or platinum-pemetrexed in EGFR T790M-Positive lung cancer. N Engl J Med 2017; 376: 629-640. 
Piccioli A, Lensing AW, Prins MH, Falanga A, Scannapieco GL, Ieran M, Cigolini M, Ambrosio GB, Monreal M, Girolami A, Prandoni P. Extensive screening for occult malignant disease in idiopathic venous thromboembolism: A prospective randomized clinical trial. J Thromb Haemost 2004; 2: 884-889.

Ramalingam SS, Vansteenkiste J, Planchard D, Cho BC, Gray JE, Ohe Y, Zhou C, Reungwetwattana T, Cheng Y, Chewaskulyong B, Shah R. Overall Survival with Osimertinib in Untreated, EGFR-Mutated Advanced NSCLC. $N$ Engl J Med 2020; 382: 41-50.

Sack GH, Levin J, Bell WR. Trousseau's syndrome and other manifestations of chronic disseminated coagulopathy in patients with neoplasms: Clinical, pathophysiologic, and therapeutic features*. Med (United States) 1977; 56: 1-37.

Sato T, Tsujino I, Ikeda D, Ieko M, Nishimura M. Trousseau's syndrome associated with tissue factor produced by pulmonary adenocarcinoma. Thorax 2006; 61: 1009-1010.

Schwartz LH, Litière S, De Vries E, Ford R, Gwyther S, Mandrekar S, Shankar L, Bogaerts J, Chen A, Dancey J, Hayes W. RECIST 1.1 - Update and clarification: From the RECIST committee. Eur J Cancer 2016; 62: 132-137.

Shiroyama T, Hayama M, Satoh S, Nasu S, Tanaka A, Morita S, Morishita N, Suzuki H, Okamoto N, Hirashima T. Successful retreatment with osimertinib after osimertinib-induced acute pulmonary embolism in a patient with lung adenocarcinoma: A case report. Respir Med Case Reports 2017; 20: 25-27.

Sorensen HT. Prognosis of cancers associated with venous thromboembolism. N Engl J Med 2000; 343: $1846-1850$.

Soria JC, Ohe Y, Vansteenkiste J, Reungwetwattana T, Chewaskulyong B, Lee KH, Dechaphunkul A, Imamura F, Nogami N, Kurata T, Okamoto I. Osimertinib in Untreated EGFR -Mutated Advanced Non-Small-Cell Lung Cancer. N Engl J Med 2018; 378: 113-125.

Trousseau A. Phlegmatia Alba Dolens. In: J.-B. Baillière et fils, editor. Proceedings of the Clin. Médicale L'hôtel-dieu Paris. 2nd ed; Paris, France; 1865; pp: 654-712.

Varki A. Trousseau's syndrome: Multiple definitions and multiple mechanisms. Blood 2007; 110: 1723-1729. 